\title{
THE REVIEW OF SYMBOLIC LOGIC
}

\section{Information for Contributors}

\begin{abstract}
Aims and Scope.The Review of Symbolic Logic is an established journal from the Association forSymbolic Logic, published in partnership with Cambridge University Press. The Review of Symbolic Logic will publish papers in: philosophical and non-classical logics, algebraic logic, and their applications in such fields as computer science, linguistics, game theory and decision theory, formal epistemology, and cognitive science; history and philosophy of logic; philosophy and methodology of mathematics, past and present.
\end{abstract}

Submission of Manuscripts. Papers must be submitted electronically via the journal's online submission system, http://asljournals.org/logon.php. If you are new to this system, please register at this site as directed. You will then be taken to your "Projects" page. Click on the button at the top of the page titled "New Submission" and follow the instructions. First choose the Review of Symbolic Logic from the Journal pull down list; afterwards please upload the files for your submission. Authors who prefer blind refereeing are invited to prepare their papers accordingly. Finally, the managing editor will assign an editor for your article. Normally we are able to get back to authors with a first verdict after a period of three months or less. The preferred file format for submissions is PDF, though other types (Postscript, .dvi, Word) are acceptable if PDF is not an option. The recommended way of creating the file is through LaTeX, as it can also be used for typesetting the final paper; see below. For more information see http://www.aslonline.org/journals-review-guide.html. If you cannot get the system to work or experience difficulties, please email aslpub@math.cornell.edu with a description of the problem. Papers already in progress will continue to be handled under the old system.

Electronic Manuscripts. The publisher encourages submission of manuscripts in LaTeX which can be used for direct typesetting. Authors using LaTeX should use the RSL LaTeX class file. This along with related files, can be obtained using anonymous FTP from ftp://ftp.cambridge.org/pub/texarchive/journals/latex/rsl-cls. If you have difficulties obtaining these files please contact dtranah@cambridge.org; there is also a help-line available via email- please contact texline@ cup.cam.ac.uk. While use of the RSL class file is preferred, plain LaTeX or TeX files can also be accepted.

Layout of Manuscripts. Manuscripts should begin with an abstract of not more than 300 words. Papers should conform to a good standard of English prose; please consult a style guide such as The Elements of Style by Strunk and White (New York: Macmillan). Do not begin sentences with a symbol or identifier name. Present programs in one of two styles: either with identifiers in italics and keywords in bold, or entirely in a fixed-width teletype font. Please supply Web URLs for the home page of each author of the paper.

References. The Harvard system of references should be used. Citations are by author's surname and year of publication, and may stand either as a noun phrase (e.g., "Curry (1993)") or as a parenthetical note (e.g., "(Curry 1933)"). List references at the end of the text in alphabetical order. A typical entry is: Curry, H.B. (1933) Apparent variables from the standpoint of mathematical logic, Ann. of Math., 34 (2): 381-404.

Artwork. To ensure that your figures are reproduced to the highest possible standards, Cambridge Journals recommends the following formats and resolutions for supplying electronic figures. LINE ARTWORK Format: tif or eps; Resolution: 1200 dpi. BLACK AND WHITE HALFTONE Format: tif; Resolution: 300 dpi. COMBINATION ARTWORK Format: tif; Resolution: 800 dpi. If you require further guidance on creating suitable electronic figures please visit http://dx.sheridan.com/guidelines/digital_art.html. Here you will find extensive guidelines on preparing artwork and gain access to an online preflighting tool where you can check to see if your figures are suitable for reproduction. If you're not providing the paper in LaTeX, please supply a list of figure captions in a separate file.

Copyediting and Proofreading. The publisher reserves the right to copyedit and proofread all articles for publication, but the corresponding author will receive page proofs for final proofreading. These should be checked and returned within three days of receipt. Only typographical or factual errors may be changed at the proof stage. The publisher reserves the right to charge authors for excessive correction of non-typographical errors.

Offprints. No paper offprints are provided, but the corresponding author will be sent a link to the pdf of the published article.

Home Page. Information about Review of Symbolic Logic may be viewed on the Cambridge University Press website at: cambridge.org/rsl or on the ASL website at: http://www.aslonline. org/journals-review.html? 


\section{Cambridge Core}

For further information about this journal

please go to the journal web site at:

cambridge.org/rsl 